\title{
O ATRASO DA HISTÓRIA: CAMPESINATO E ENGAJAMENTO (1964/1996)
}

\author{
EL ATRASO DE LA HISTORIA: CAMPESINADO Y COMPROMISO (1964/1996)
}

HISTORY'S DELAY: PEASANTS AND POLITICAL ENGAGEMENT (1964/1996)

LE RETARD DE L'HISTOIRE : PAYSANNERIE ET ENGAGEMENT (1964/1996)

历史的落后 : 农民问题与农民参与政治 (1964/1996)

DOI: 10.5533/1984-2503-20146101

\section{Márcia Maria Menendes Motta ${ }^{1}$}

\section{RESUMO}

É difícil imaginar qual é de fato a relevância do conhecimento histórico para os movimentos sociais. Quase sempre, os historiadores recusam-se a fazer alguma análise sobre a historicidade de determinada luta no campo, argumentando que afinal de contas a história não estuda o passado para vender profecias. No entanto, é preciso ser particularmente insensível para desconhecer a importância que a História adquire na legitimidade e a legalidade dos movimentos sociais, em particular daqueles que estiveram ou estão vinculados à luta pela reforma agrária. A questão, porém, não é simples e isso por uma série de razões que vou tentar explorar neste artigo. Nele, eu analiso o tema da reforma agrária e do conceito de campesinato nas conjunturas históricas dos anos sessenta até os anos 90. Parto aqui do pressuposto que é possível encontrar alguns pontos de contato que expliquem a pouca presença da História nas reflexões acadêmicas que procuraram legitimar a atuação das lutas no campo brasileiro.

Palavras-chave: História, campesinato, reforma agrária.

\footnotetext{
${ }^{1}$ Professora do Departamento e do Programa de Pós Graduação em História da Universidade Federal Fluminense (UFF). Pesquisadora do Conselho Nacional de Desenvolvimento Científico e Tecnológico do Brasil (CNPq) e Pesquisadora da Fundação de Amparo à Pesquisa do Estado do Rio de Janeiro, Cientista do Nosso Estado (FAPERJ). E-mail: menendesmotta@ig.com.br.
} 


\section{RESUMEN}

Es difícil imaginar cual es de hecho la relevancia del conocimiento histórico para los movimientos sociales. Casi siempre, los historiadores se niegan a hacer algún análisis sobre la historicidad de determinada lucha en el campo, argumentando que a fin de cuentas la historia no estudia el pasado para vender profecías. Sin embargo, es necesario ser particularmente indeclinable para desconocer la importancia que la Historia adquiere en la legitimidad y en la legalidad de los movimientos sociales, en particular de aquellos que estuvieron o están vinculados a la lucha por la reforma agraria. Pero, esta no es una cuestión sencilla en razón de aspectos que intentaré explorar en este artículo. Aquí analizo el tema de la reforma agraria y del concepto de campesinado en las coyunturas históricas desde los años 1960 hasta los años 1990. Parto del presupuesto que es posible encontrar algunos puntos de contacto que expliquen la poca presencia de la Historia en las reflexiones académicas que procuraron legitimar la actuación de las luchas en el campo brasileño.

Palabras clave: Historia, campesinado, reforma agraria.

\section{ABSTRACT}

It is difficult to imagine the actual relevance of historical knowledge to social movements. Historians almost always refuse to conduct any kind of analysis on the historicity of rural struggles, arguing that, ultimately, history does not study the past to sell prophecies. We would, however, have to be particularly insensitive not to recognize the importance which history acquires in the legitimacy and legality of social movements, in particular those which were or are linked to the struggle for agricultural reforms. The issue, however, is far from simple for a series of reasons that I will attempt to explore in this article. In doing so, I analyze the subject of agricultural reform and the concept of the peasant during historic conjunctures from the 1960s to the 1990s. I depart from the presumption that it is possible to encounter several points of contact which explain the scant presence of history in academic reflections seeking to legitimize the role played by struggles in rural Brazil.

Key words: History, peasants, agricultural reforms.

\section{RÉSUMÉ}

II est difficile d'imaginer quelle est réellement la pertinence du savoir historique pour les mouvements sociaux. Les historiens se refusent le plus souvent à faire une quelconque analyse 
de l'historicité de telle ou telle lutte paysanne, en avançant l'argument selon lequel l'Histoire n'étudie pas le passé pour vendre des prophéties. Toutefois, il faut être particulièrement insensible pour méconnaître l'importance que l'Histoire acquiert dans la légitimité et la légalité des mouvements sociaux, en particulier ceux qui ont été, ou sont encore, liés à la lutte en faveur de la réforme agraire. La question n'est néanmoins pas simple, et ce pour toute une série de raisons que cet article veut explorer. Nous analyserons ici le thème de la réforme agraire et le concept de paysannerie au sein des conjonctures historiques des années 1960 aux années 1990. On partira du présupposé de ce qu'il est possible de trouver certains points de convergence qui expliquent la rareté du recours à l'Histoire dans les réflexions académiques qui cherchent à légitimer les luttes dans les zones rurales brésiliennes.

Mots-clés : Histoire, paysannerie, réforme agraire.

\section{摘要}

要想了解具体哪一个历史要素对社会运动有何种矢联是件困难的。历史学家总是避免对农村政治斗 争进行历史地位评价, 其借口是, 研究历史不是为了兒售对未来的预言。尽管如此, 乡村的有矢土 地改革的运动在历史发展中有其一席之地, 书写历史如果不承认农村围绕土改而发生政治斗争, 其 合法性就会有疑问。可是问题不是如此简单，本文作者对1960年代到1990年代关于土改问题的争论 进行了分析，同时

对“农民”的概念的演化做了探讨。作者的目的是探讨为何巴西历史学术界中很少研究乡村阶级斗争的 合法性的何因。

关键词: 历史, 农民, 乡村土地改革

\section{1- Reforma agrária e campesinato no contexto do golpe de 64.}

A reforma agrária é um conceito de múltiplos significados. Ao contrário do que o imaginamos, ele pode ser acionado para defender uma mudança radical no padrão de distribuição de terras, como pode também ser mencionado para a definição de determinada política para o campo que não necessariamente incorpora uma distribuição equitativa da propriedade rural. Neste sentido, há dinâmicas muito distintas que operam a partir de uma determinada visão sobre o que significa o conceito de reforma².

\footnotetext{
${ }^{2}$ Os casos clássicos são muito interessantes para recuperarmos as múltiplas formas de incorporar o campo no processo de modernização. Para tanto, vide. Moore Junior, Barrignton (1983). As origens sociais da ditadura e da democracia. Senhores e Camponeses na construção do mundo moderno, São Paulo: Martins Fontes.
} 
Assim, por exemplo, às vésperas do golpe de 1964, vários atores sociais usavam este termo para defender políticas totalmente diversas, quando não opostas. No início daquele ano, o Jornal da Manhã, por exemplo, assim informava:

\begin{abstract}
Ninguém ignora a necessidade social dessa reforma, para redimir de sua atual condição de párias da vida nacional a maioria do povo brasileiro: a população dos campos. Mas sempre insistimos, em numerosos editoriais, no fato de que o motivo social não é o único do reformismo. A solução do problema é de importância igual para as populações urbanas que crescem tempestuosamente e cuja alimentação seria em breve impossível sem uma mudança radical dos hábitos de produção - $e$ de não produção - da lavoura brasileira. O latifúndio é apenas uma condição da qual vive a monocultura. Mas monocultura significa déficit de produção de alimentos, em favor da agricultura de exportação. Significa dependência das oscilações de preços de mercados estrangeiros. Significa baixo nível de vida nos campos, significa praticamente ausência de mercado interno. E o mercado interno é a conditio sine qua non da industrialização ${ }^{3}$.
\end{abstract}

Nas páginas do Correio da Manhã se desnudavam uma dada concepção de reforma que atenderia, não somente aos trabalhadores rurais, mas também os citadinos. A ideia de que a reforma seria necessária para o desenvolvimento do país havia deitado raízes em várias interpretações sobre os rumos da modernização do Brasil. Para muitos, ela era condição sine qua non para consolidar o processo de industrialização em curso 4 .

Àquela visão sobre a reforma agrária expressa pelo Correio da Manhã se contrapunha, por exemplo, a definição apoiada pelo movimento Tradição, Família e Propriedade. Em oposição a uma reforma agrária radical, havia a defesa de outra, marcada por uma visão católica conservadora que legitimava a propriedade privada ${ }^{5}$. Exemplo emblemático daquela visão era o livro: Reforma Agrária: questão de consciência, escrito por Dom Antonio de Castro Mayer.

\footnotetext{
${ }^{3}$ Correio da Manhã, 01 de janeiro de 1964.

${ }^{4}$ A noção bipolar entre um rural atrasado $X$ um urbano moderno foi definitivamente superada quando da publicação do artigo de Francisco de Oliveira. "A economia brasileira.Crítica à razão dualista", publicado pela primeira vez em 1972, pelo CEBRAP. Oliveira, Francisco de (2003). Crítica À Razão Dualista - O Ornitorrinco, Boitempo.

${ }^{5}$ Não há como negar que havia católicos engajados na proposta de uma reforma agrária radical. Nos anos 70 e 80, a Editora franciscana Vozes publicou centenas de livros sobre a questão agrária no Brasil. Muitos desses livros tornaram-se referência obrigatória para os estudiosos do universo rural. Entre tantos: Melo, Maria da Conceição D'Incaio (1975). O Bóia-Fria. Acumulação e Miséria, Petrópolis: Vozes. Trata-se de um dos primeiros (senão o primeiro) estudo sobre os chamados bóias-fria; trabalhadores preferencialmente do setor canavieiro, submetidos a duras condições de empregabilidade, nas épocas das colheitas. O caráter sazonal da atividade e principalmente o fato de comerem sua comida fria, depositada em marmitas, consagraram o termo para o centro sul do Brasil; principalmente nos anos da chamada modernização agrícola do período da ditadura.

Agradeço ao parecerista a imprescindível lembrança acerca da Editora Vozes.
} 
Na edição comemorativa dos 50 anos de publicação do livro, com a Introdução do Príncipe D. Bertrand de Orleans e Bragança, os defensores da obra ainda persistem em afirmar que o livro desnuda uma questão de consciência em favor da propriedade privada. Segundo os informes:

Durante os governos dos presidentes Jânio Quadros e João Goulart, iniciou-se uma luta contra-revolucionária para impedir a implantação no Brasil da Reforma Agrária socialista e confiscatória. No cerne dessa luta, o livro Reforma Agrária Questão de Consciência, cuja solidez doutrinária muitas personalidades reconhecem ${ }^{6}$.

Ainda segundo os defensores daquela concepção de reforma agrária, aquela luta ainda persiste, pois "o confisco de terras pelo Estado transgride dois Mandamentos da Lei de Deus: "Não roubarás" e "Não cobiçarás as coisas alheia"! Ainda segundo um site católico, o livro teria sido um best seller nacional, sendo tal fato divulgado pelo jornal $O$ Globo, em de 30 de junho de $1961 .^{8}$

Não nos cabe aqui discutir o impacto da defesa em torno de uma determinada concepção de reforma agrária no processo que culminou no Golpe de 1964. Ainda que sejam marcadamente recentes os estudos em História voltados para o período da ditadura, mais uma vez inaugurados pela sociologia rural, já se sabe hoje que aquele período foi particularmente trágico para os camponeses, produzindo uma amnésia social intimamente relacionada à luta pela sobrevivência física de muitos daqueles homens. A historiografia sobre a chamada História do Tempo Presente já incorpora mais explicitamente os problemas que envolviam o campo e as distintas concepções de reforma agrária em disputa ${ }^{9}$. Por conseguinte, alguns historiadores têm somado esforços para compreender as dinâmicas da luta no campo e seu desdobramento na legislação produzida ao longo da ditadura ${ }^{10}$.

\footnotetext{
${ }^{6}$ http://resistenciamilitar.blogspot.com.br/2011/03/reforma-agraria-questao-de-consciencia.html. Retirado em 03 de setembro de 2013.

7 lbidem.

${ }^{8}$ http://ccatolico.qualinfonet.com.br/site/?p=5599 Retirado em 03 de setembro de 2013.

9 Neste sentido, a atuação das Ligas Camponesas têm sido revistas, não mais como reféns do jogo político partidário, mas também como concepções de justiça e de direito à terra presentes nas comunidades rurais. Neste sentido, vide Rangel, Socorro (2000). Medo da morte e esperança de vida: uma história das Ligas Camponesas. Dissertação (Mestrado em História) - UNICAMP. Motta, Márcia; Esteves, Carlos Leandro (2008). "Ligas Camponesas: História de uma luta (des)conhecida". In Motta, Márcia; Zarth, Paulo. Formas de resistência camponesa. vol. II. São Paulo, UNESP, p. 243-257.

${ }^{10}$ A maior parte destes historiadores é influenciada pelas pesquisas inaugurais da socióloga Regina Bruno. Bruno, Regina (1995). "O Estatuto da Terra: entre a conciliação e o confronto". In Estudos Sociedade e Agricultura (UFRJ), v. 4, p. 5-31.
} 
Após o golpe e em decorrência de intensos debates produzidos no interior do grupo político que assumiu o poder, foi instituído o Estatuto da Terra. Por esta lei, a Reforma Agrária foi definida como "um conjunto de medidas que visem a promover melhor distribuição da terra mediante modificação no regime de sua posse e uso, a fim de atender aos princípios de justiça social e do aumento da produtividade"11.

Regina Bruno chama a atenção para os mecanismos usados pelos grandes proprietários para controlar a acepção do conceito, questionando - em todo o processo de votação da lei - os usos e os significados de termos como problema agrário (o que implica modificação na estrutura de distribuição de terras), problema rural (que remete às condições de vida dos trabalhadores), além da noção de justiça, usos sociais e valor da terra $^{12}$. Assim, o conceito de reforma agrária presente no Estatuto teria sido o resultado de embates e concepções sobre a reformulação fundiária que são dificilmente perceptíveis numa primeira leitura da lei.

Em suma, o uso do termo reforma agrária não foi e não é suficiente para se colocar do outro lado da cerca, isto é, o conceito apenas aponta certo compromisso com a necessidade de reformulação fundiária, mas isso não implica automaticamente uma proposta que atenda aos pobres do campo.

Em segundo lugar e em particular no caso brasileiro, o uso daquele conceito não esteve e não está atrelado ao uso de outro conceito, amplamente empregado em outras conjunturas históricas e entre outros campos de conhecimento como a sociologia rural e a antropologia rural. Refiro-me ao termo campesinato, raramente usado pelos historiadores. Seja pela aposta de sua inexistência histórica no Brasil, seja pela dificuldade em defesa de um termo reconhecidamente universal, é mais freqüente encontrarmos uma defesa de distribuição de terras, a partir de uma aposta na configuração étnica da questão.

É preciso lembrar, antes de tudo, que o conceito de campesinato desaparece e sequer é definido no Estatuto da Terra de 1964. Ao se referirem aos homens do campo, o Estatuto opera com o termo trabalhador rural, sem reconhecer - no texto da lei centenas de pequenos posseiros e lavradores que passaram a se autodefinir como camponeses, em grande parte como resultado da luta pela reforma agrária levada a cabo pelas Ligas Camponesas. Assim, segundo o Estatuto, é dever do poder público:

\footnotetext{
${ }^{11}$ LEI № 4.504, DE 30 DE NOVEMBRO DE 1964. http://www.planalto.gov.br/ccivil 03/leis/L4504compilada.htm

${ }^{12}$ Bruno, R. (1995). Op. cit.
} 
(...) promover e criar as condições de acesso do trabalhador rural à propriedade da terra economicamente útil, de preferência nas regiões onde habita, ou, quando as circunstâncias regionais, o aconselhem em zonas previamente ajustadas na forma do disposto na regulamentação desta $L e i^{13}$.

Ao definir a unidade de tipo camponesa, o Estatuto definiu-o como "propriedade familiar", enquanto um imóvel rural que está

(...) direta e pessoalmente explorado pelo agricultor e sua família, Ihes absorva toda a força de trabalho, garantindo-lhes a subsistência e o progresso social e econômico, com área máxima fixada para cada região e tipo de exploração, e eventualmente trabalho com a ajuda de terceiros ${ }^{14}$.

Há que se considerar ainda que o intenso debate no interior do Partido Comunista, nos anos 50 e início da década seguinte, acerca das mobilizações rurais e do papel dos homens do campo na desejada revolução havia legitimado a consagração do conceito de camponês e sua atuação, enquanto ator político. No entanto, após o golpe, um dos mais importantes historiadores daqueles anos e co-participe do Partido Comunista, Caio Prado Junior, não somente desnudara as concepções teóricas que norteavam a participação de vários integrantes do Partido Comunista na luta camponesa, como desautorizaria o conceito de reforma agrária:

Não foram as agitações dos foreiros e ocupantes de terras, e sim a ampla mobilização dos trabalhadores canavieiros que seguiu e acompanhou aquelas agitações, e na qual não se propôs a questão da terra, e sim a luta por melhores condições de trabalho e emprego nos engenhos e usinas ${ }^{15}$.

Logo, há duas linhas aparentemente paralelas que se unem para a pouca presença da História nos estudos sobre o campesinato. Em primeiro, a ausência do conceito na mais importante legislação produzida no período da ditadura. Em segundo, a consagração da obra de Caio Prado Junior e sua insistência em minimizar a atuação dos pobres do campo, reconhecidos enquanto camponeses pelos movimentos rurais. Sem nenhuma evidência empírica, Prado Jr defendeu acertadamente a impropriedade teórica do uso de remanescentes feudais no campo brasileiro, mas também expressou sua discordância em relação à reforma agrária, sublimando a atuação dos camponeses.

\footnotetext{
${ }^{13}$ Estatuto...

${ }^{14}$ Estatuto...

${ }^{15}$ Prado Jr, Caio.(1996). A Revolução Brasileira. 2ª edição, São Paulo: Editora Brasiliense, p. 233.
} 


\section{2- O campesinato na História no contexto da ditadura}

Mas é no contexto da ditadura que encontramos também um livro inaugural sobre a temática de uma História do campesinato no Brasil: Agricultura, escravidão \& Capitalismo, publicado pela primeira vez em 1979, pela editora franciscana Vozes ${ }^{16}$. Ciro Cardoso advogava a existência de duas modalidades de brecha: aquela ligada à economia independente dos cativos fugidos que se organizavam em quilombos e os pequenos lotes de terra concedidos em usufruto ao escravo das fazendas, com exceção dos domésticos. Cardoso reconhecia ainda, apoiando-se nos estudos de Sidney Mintz ${ }^{17}$, a possibilidade da existência de um campesinato não proprietário (muitos instalados em terras devolutas), de um campesinato sem terras, como os lavradores arrendatários das fazendas de açúcar e os camponeses proprietários. De qualquer forma, ele afirmava que não iria discutir estas outras possibilidades de existência camponesa, e sim 0 protocampesinato escravo, termo originalmente criado por Mintz.

A opção de utilizar um prefixo - proto - para se referir às possibilidades de uso da terra pelos cativos, antes de iluminar a questão, acabava por obscurecê-la, pois o prefixo é um morfema que tem como objetivo alterar o significado da palavra. Logo, a palavra protocampesinato objetiva afirmar uma pré-história camponesa. O que isso significaria? Haveria,no passado colonial, pessoas que poderiam ser ao mesmo tempo escravos e camponeses? Aqueles que fugiam do cativeiro tornar-se-iam camponeses por inteiro? Como lidar com a fluidez das definições?

O fio condutor da análise era: conceitualmente é possível ser escravo e camponês? Para responder afirmativamente a questão, Cardoso apoiava-se no estudo de Archetti, Fossum e Reinton que em sua análise sobre economia camponesa haviam desenvolvido o conceito de autonomia estrutural: a) segurança no acesso à parcela; b) grau de relação direta com o mercado e c) grau de gestão sobre a parcela quanto à distribuição dos recursos disponíveis ${ }^{18}$. Em conclusão, Cardoso considerava que os escravos-

\footnotetext{
${ }^{16}$ Cardoso, Ciro (1979). Agricultura, Escravidão e Capitalismo, Petrópolis: Vozes.

17, Sidney Mintz (1974). "The Origins of Reconstituted Peasantries". In Caribbean Transformation. Chicago, Aldine, p. 146-156. Sidney Mintz é considerado um dos mais influentes antropólogos norte-americanos para os estudos sobre o campesinato. Em 2003, publicou o seu livro em português. Sidney Mintz (2003). O poder amargo do açúcar. Recife: Editora da Universidade Federal de Pernambuco.

18 Eduardo Archetti et alli (1970). "Agrarian Structure and Peasant Autonomy". In Journal of Peace Research7(3): 185-195.
} 
camponeses tinham alta autonomia estrutural, levando-se em conta as dimensões definidas por aqueles autores que haviam estudado as experiências camponesas na América Latina no século $X X$ e nenhuma referência fizeram ao passado escravista no continente. Logo, o uso do conceito de autonomia estrutural era empregado para outro contexto histórico.

É importante destacar ainda que Agricultura, Escravidão e Capitalismo fora publicado em 1979 pela Editora Vozes, num contexto de profunda repressão política. Era certamente muito complicado afirmar a existência de uma História do campesinato no Brasil e talvez não tenha sido à toa que Cardoso também afirmara que o termo era demasiadamente polêmico. De qualquer forma, em plena ditadura, muitos autores buscaram entender o rural e as raízes socioeconômicas da pobreza no campo e da concentração fundiária no país. A criação da Comissão Pastoral da Terra,em 1975, cuja missão era a de identificar as mazelas rurais sofridas pelos camponeses e lhe fornecer apoio, inclusive jurídico nas demandas contra os latifundiários, contava com 0 engajamento de muitos intelectuais em ascensão, como o sociólogo José de Souza Martins ${ }^{19}$.

Além disso, não se pode ignorar que Agricultura, Escravidão e Capitalismo havia sido escrito por Cardoso e se tornara o aporte teórico de uma geração de historiadores envolvidos na consolidação da linha de História agrária na Universidade Federal Fluminense. É impossível ignorar ou mesmo minimizar o protagonismo de Maria Yedda Leite Linhares neste processo 20 .

Qualquer que tenha sido os motivos que levaram ou não uma geração de pesquisadores a se envolverem com este tema ainda em plena ditadura, é sintomático perceber a pouca presença da História, enquanto campo científico, nos estudos do que poderíamos chamar de História social do campesinato ou mesmo de uma História agrária, tal como desejara a equipe em torno de Leite Linhares e Ciro Cardoso. Se isso é fato. As coisas melhoraram com a redemocratização e, a partir de 1988, com a nova Constituição? Em outras palavras, o processo de redemocratização deu mais segurança aos estudos

\footnotetext{
${ }^{19}$ Martins é autor de dezenas de livros sobre o rural e teve influência marcante nos estudos sobre o campesinato no país.

${ }^{20}$ É impossível discutir aqui a trajetória de Maria Yedda Leite Linhares em sua relação com a criação do CPDA e posteriormente com a linha de pesquisa em História Agrária na UFF. Para uma primeira análise sobre o tema, vide: Motta, Márcia (2010). "O rural na História do Brasil (dos anos 80 aos trabalhos mais recentes)" In Revista Portuguesa de História, Coimbra, p. 175-191.
} 
sobre o rural, o que me permitiu que uma nova geração de historiadores se interessasse pela temática?

\section{3- Os anos da redemocratização e a questão agrária}

Em fins dos anos 80, a questão agrária certamente ganhou uma visibilidade pouco frequente, principalmente em razão das polêmicas envolvendo o tema da reforma agrária na Constituinte de 1987 e a Constituição no ano seguinte. Nos anos da abertura, movimentos sociais no campo e na cidade, MST, PT, CUT, passaram a representar segmentos gestados (e sufocados) durante a ditadura. A reforma agrária retornou à cena política nacional, com novos atores sociais surgidos durante as transformações econômicas iniciadas nos anos 60. Com a modernização tecnológica consolidada nos anos de chumbo, vieram à luz os chamados empresários agroindustriais e - na outra face da moeda - os bóias-frias.

Desde 1884, quando se tem inicio à campanha de Tancredo Neves à presidência do país, a questão da reforma agrária tornou-se um dos temas mais discutidos para a elaboração da proposta de ação do futuro governo. A intenção última era a de avançar alguns dos dispositivos presentes no Estatuto da Terra de 1964 diretamente ligados à reformulação da estrutura fundiária. Segundo José Gomes da Silva, no Simpósio Nacional do PMDB sobre Agricultura e Meio Ambiente, realizado em Curitiba de 15 a 17 de outubro de 1984, entre as cinco propostas apresentadas para o debate, a da reforma agrária aparecia em primeiro lugar .

Após a morte de Tancredo, José Sarney herdou o tema da reforma agrária como um de seus principais compromissos políticos. No entanto, segundo os estudiosos, a composição da aliança do governo inviabilizou qualquer projeto mais radical sobre o tema. De todo modo, em 1985, é escrita a primeira versão do Plano Nacional de Reforma Agrária, não à toa apresentado ao IV Congresso Nacional de Trabalhadores Rurais, em Brasília, no dia 26 de maio daquele ano. Anunciado durante o IV Congresso da CONTAG ${ }^{21}$, a "proposta" de reforma agrária provocara uma imediata reação dos proprietários rurais e setores empresariais ${ }^{22}$.

\footnotetext{
${ }^{21}$ A Confederação dos Trabalhadores na Agricultura foi criada em dezembro de 1963, poucos meses antes do golpe do ano seguinte.

${ }_{22}^{2}$ Silva, Gomes da (1985). Para entender o Plano Nacional de Reforma Agrária, Rio de Janeiro: Brasiliense.
} 
O objetivo de alterar a estrutura fundiária do país apareceu claramente na primpeira proposta, com a previsão de assentar três milhões de famílias em dez anos e na intenção de utilizar o dispositivo da desapropriação para garantir a função social da terra, tal como previra o Estatuto da Terra. Havia ainda o objetivo de criar mecanismos para consagrar as propriedades comunitárias e associativas, rompendo com o paradigma da propriedade individual e absoluta. Propunha-se assim o princípio da "consessão de uso das terras públicas - devolutas ou não-para fins de colonização e de reforma agrária, grantindo que a terra não seria passível de venda a terceiros,23

Entre a proposta apresentada e aquela aprovada com o nome de Plano Nacional de Reforma Agrária havia marcantes diferenças que inviabilizaram na prática qualquer alteração da estrutura fundiária. Além disso, sem a delimitação das áreas prioritárias, 0 Plano Nacional de Reforma Agrária do governo Sarney não alterou a estturua fundiária do pa'si. O mesmo pode ser dito em relação aos embates na Contituinte. A exclusão do chamado "latifúndio produtivo" para fins de desapropriação, significou que a função econômica de grandes latifúndios se sobrepôs ao princípio da função social da propriedade, anteriormente expresso no Estatuto da Terra, de $1964^{24}$.

No entanto, o tema da reforma agrária era algo sempre lembrado pela população. Segundo um dos mais importantes estudiosos da Constituinte de 1987, este tema foi o que recebeu o maior número de assinaturas na fase de Emenda Popular, nada menos do que um milhão e duzentas mil. Ainda segundo o mesmo autor, em uma pesquisa realizada pelo IBOPE (publicada pelo Jornal do Brasil em 1987), foram arrolados 15 temas que "deveriam merecer maior importância na Constituição, caso o entrevistado pudesse ajudar a prepará-la”. A Reforma Agrária ficou em terceiro lugar, como 38\% das preferências, logo depois da distribuição de renda, com $40 \%$ e do ensino gratuito, com $46 \%{ }^{25}$.

Em um texto publicado em 2006, eu argumentei que a consagração do termo remanescente de quilombo desnuda as ambigüidades presentes na generalização do conceito em sua relação com a Reforma Agrária no Brasil ${ }^{26}$. A meu ver, ao procurar

\footnotetext{
${ }^{23}$ Ibidem, p. 29.

${ }^{24}$ Silva, José Gomes da Silva (1989). Buraco Negro. A Reforma Agrária a Constituinte, Rio de Janeiro: Paz e Terra.

25 Ibidem, p.14.

26 Motta, Márcia (2006). "Brecha negra em livro Branco: artigo 68, remanescentes de quilombos e grilagens no Brasil”. In Mendonça, Sonia. Estado e historiografia no Brasil Niterói: EDUFF, p. 231-255.
} 
atender a demanda pelo direito à terra em várias comunidades pobres do país, a utilização do termo por antropólogos e historiadores anuncia e denuncia uma reforma agrária em migalhas ${ }^{27}$ e estreita nossa visão sobre o fenômeno das grilagens no país.

Assim, a meu ver, a despeito de tamanhos esforços, ainda são débeis os avanços consagrados na Carta Magna de 1988 em relação às questões relativas ao universo rural e suas conseqüências são visíveis na opção pelo agro-negócio nas últimas décadas. Ela não aperfeiçoou o conceito de função social da propriedade, determinando que a desapropriação dar-se- ia "mediante justa e prévia indenização em dinheiro, ressalvado os casos previstos nesta Constituição"28. Pelo artigo 184, estabeleceu-se ainda que "Compete a União desapropriar por interesse social, para fins de reforma agrária, o imóvel rural que não esteja cumprindo sua função social, mediante prévia e justa indenização em títulos da dívida agrária"29. No parágrafo 1ํacordou-se também que as benfeitorias "úteis e necessárias"(sic!) seriam indenizadas em dinheiro ${ }^{30}$. A Constituição tampouco reconheceu - no texto da lei - a necessidade de se limitar à ocupação de grandes extensões de terras para um único indivíduo ou empresa.

Batizada com o título de Constituição Cidadã por Ulisses Guimarães, ela, segundo o sociólogo Gomes Silva, "aprofundou o buraco da desigualdade, impedindo que a questão agrária pudesse ser resolvida pacificamente"31. Ela introduziu "o bloqueio da impenhorabilidade" da propriedade produtiva, a grande bandeira da UDR ${ }^{32}$. Neste sentido, pelo artigo 185, "são insuscetíveis de desapropriação para fins de reforma agrária: l- a pequena e média propriedade rural, assim definida em lei, desde que proprietário não possua outra; II- a propriedade produtiva"33. Em seu parágrafo único estabeleceu-se que "A lei garantirá tratamento especial à propriedade produtiva e fixará normas para o

\footnotetext{
${ }^{27}$ Neves, Delma Pessanha (1997). Assentamento rural: reforma agrária em migalhas, Niterói: EDUFF. O trabalho de Pessanha analisa a falência das usinas de Campos de Goitacases, suas desapropriações e a transformação de antigos trabalhadores em assentados. Em suma, seu texto não faz referência aos remanescentes de quilombos, nem à Constituição de 1988, por tratar-se dos desdobramentos do PNRA, de 1985. No entanto, suas ilações iluminaram minhas reflexões sobre o tema.

${ }_{28}$ Constituição do Brasil (2004), Rio de Janeiro: Editora Auriverde. Titulo II, Dos Direitos e Garantias Fundamentais. Capitulo I. dos direitos e deveres individuais e coletivos. Art. 5o ,XXIV, p. 10.

29. Titulo VII. Da Ordem Econômica e Financeira. Capitulo III Da política agrícola e fundiária e da reforma agrária artigo 184. Ibidem, p. 110

${ }_{30}$ Ibidem.

31 Silva, Gomes da (1989). Op. cit, p.199.

32 Ibidem, p.201

33. Titulo VII. Da Ordem Econômica e Financeira. Capitulo III Da política agrícola e fundiária e da reforma agrária. Art 185, Constituição do Brasil. Op. cit, p. 111.
} 
cumprimento dos requisitos relativos a sua função social' ${ }^{34}$. Em outras palavras, a Carta transferiu para legislações complementares as normas definidoras dos requisitos necessários para o cumprimento da função social da propriedade, estabelecido no artigo seguinte, o de número 186. Além disso, o termo - propriedade produtiva - constitui-se numa deformação conceitual e uma impropriedade semântica, escondendo, nas palavras de Gomes da Silva, uma armadilha legal ${ }^{35}$.

Tampouco há no texto da lei, uma referência direta às grilagens, ainda que muitos soubessem que boa parte das chamadas propriedades produtivas havia sido instaladas em áreas, antes objeto de um complexo processo de grilagens em terras devolutas. Isso significa dizer que para fazer jus aos interesses da UDR, os parlamentares pouco fizeram para condenar e punir a prática centenária de ocupação ilegal de terras no país ${ }^{36}$.

Mas é preciso reconhecer alguns avanços propiciados pela Constituição, em relação à discriminação das terras indígenas, por exemplo. Pela primeira vez na história constitucional do país, há um capítulo inteiro dedicado às sociedades indígenas, além de artigos esparsos. É fato, porém, que a Constituição estabeleceu também o prazo de cinco anos, a partir da sua promulgação, para o termo da demarcação das terras indígenas ${ }^{37}$. Passados mais de duas dezenas de anos, o processo ainda não foi concluído, revelando as dificuldades de se colocar em prática os propósitos ali estabelecidos. Ainda assim, é sempre bom frisar que a despeito das enormes dificuldades no processo de demarcação daquelas terras, o texto da Carta Magna compartilha uma crítica ao racismo e as diversas formas de preconceito.

À crítica ao racismo e a valorização das identidades étnicas se expressam também no artigo 68 da Constituição, no Ato das Disposições Constitucionais Transitórias. De acordo com o mencionado artigo, "aos remanescentes das comunidades de quilombos que estejam ocupando suas terras é reconhecida a propriedade definitiva, devendo o

\footnotetext{
34 Ibidem.

${ }^{35}$ Silva, Gomes da (1989). Op. cit, p. 202.

${ }^{36}$ Vide o exemplar livro: Bruno, Regina (1997). Senhores da terra, senhores da guerra: a nova face política das elites agroindustriais no Brasil, Rio de Janeiro: Forense Universitária.

${ }^{37}$ Ato das Disposições Constitucionais Transitórias Artigo 67 "A União concluirá a demarcação das terras indígenas no prazo de cinco anos a partir da promulgação da Constituição". Constituição do Brasil. Op.cit, p. 155.
} 
Estado emitir-lhes os títulos respectivos'38. Pela primeira vez na história do país, a Carta Magna admitiu o direito à terra de descendentes de cativos e ratificou a propriedade coletiva de suas posses. Além disso, ao consagrar tal direito a partir de um viés cultural, a Constituição ainda determinou no artigo 216 a proteção das manifestações das culturas populares, indígenas e afrodescendentes, estabelecendo no seu parágrafo quinto que "ficam tombados todos os documentos e os sítios detentores de reminiscências históricas dos antigos quilombos"39.

Não obstante, exatamente por permitir uma reforma agrária em migalhas, a Constituição consagrou políticas sociais compensatórias, a partir daquilo que se convencionou chamar de judicialização da questão agrária. Significa dizer: para que os pobres do campo possam vir a ter o título de propriedade de suas posses é ainda preciso que eles se inscrevam na categorização de remanescente de quilombos, brecha possível para o alcance de um direito que lhe é historicamente negado.

O que escrevera em 2006 ainda se constitui - ao menos para mim - uma evidência inquestionável. A Constituição criou brechas para o reconhecimento das terras indígenas e dos chamados quilombolas, mas também criou uma armadilha jurídica. Ao contrário dos que detêm enormes parcelas de terras, para os pobres é preciso se circunscrever numa identidade étnica, real ou imaginária - pouco importa - para terem alguma chance de acesso a um pequeno pedaço de terra. Além disso, a nova geração de historiadores, em sua maioria distantes dos temas que envolvem à questão agrária brasileira, desconhece todos os embates que foram postos a nu, quando da Constituinte de 1988. Entre as várias querelas, não há dúvida de que as discussões sobre o que iríamos chamar de Reforma Agrária foram marcantes, assim como também foi memorável a derrota sofrida pelos adeptos de uma reforma agrária à esquerda. Assim, o que parece hoje uma vitória, daí a consagração do termo Constituição Cidadã, foi vista como uma marcante derrota pelos setores de esquerda que elaboraram propostas de reforma agrária, encaminhadas aos constituintes. Dois dos principais livros publicados naquele período sobre o tema da Constituição são por mais sugestivos: O já citado O Buraco Negro e o de José Eli ds Veiga, A reforma que virou suco, de $1990^{40}$.

\footnotetext{
${ }^{38}$ Capitulo III. Titulo VIII. Da Ordem Social. Da educação, da cultura e do desporto. Seção II. Da cultura. Artigo 216, Constituição do Brasil. Op. cit, p. 124. .

39 lbidem.

${ }^{40}$ Veiga, José Eli da (1990). A Reforma que virou suco. Uma introdução ao dilema agrário do Brasil.
} 
Em recente estudo, os pesquisadores André Beltrão, Salete da Dalt e Victo Hugo Gouveia publicaram um trabalho intitulado: Comunidades quilombolas no Brasil. Segundo estes autores, apenas 6\% dos 2.058 entrevistados informam que a terra é coletiva, "na contramão do formato obrigatório para a titulação das áreas quilombolas", tal como definidos nas legislações e o INCRA ${ }^{41}$. Um percentual de $49 \%$ define suas terras como próprias ou de herança e 6\% por posse. Dos entrevistados, 57,7\% se declaram pretos, $21,7 \%$ se declaram pardos. Logo, a configuração étnica é um elemento importante na identificação das comunidades pobres, mas não é nada desprezível os critérios pautados na legitimidade de seu acesso à terra, como próprias (o que significa uma pretérita ocupação de seus antepassados, transmitida via herança) ou um apossamento mais recente. Em outras palavras, o significado étnico não foi acompanhado por uma aceitação dos critérios definidores de terras coletivas - tal como exigido em lei -, ainda que obviamente trata-se de comunidades rurais, com sistema de transmissão de patrimônio (ou ausência de) muito diferentes dos nossos.

De qualquer forma, a despeito dos limites da Carta Constitucional de 1988 em relação à questão agrária passamos a viver num regime democrático. Era de se esperar, portanto, de que os esforços inauguradores de Ciro Cardoso e de alguns outros estudiosos se firmassem no campo científico da História. Seria razoável supor que após longos anos de ditadura, os historiadores estivessem em condições mais favoráveis para discutir o tema do campesinato, transformando as propostas inaugurais de Maria Yedda e Ciro Cardoso numa reflexão mais densa, haja vista o processo de profissionalização do saber histórico e a consolidação de vários programas de pós graduação no país. Neste sentido, seria esperado que conceitos como campesinato, reforma agrária aparecessem como palavras-chave utilizadas pelos historiadores, o que demonstraria um crescente interesse pelo tema.

Em vista destas informações, o que esperar dos historiadores? Para responder a pergunta, eu busquei o levantamento realizado pela ANPUH em 1996 e organizado por Holien Bezerra \& Edilson dos Santos. Quem é quem na História. Pesquisadores e Pesquisas no Brasil. Dos 456 investigadores que responderam ao questionário, 444 informaram em qual linha de pesquisa se inseriam. Apesar da pluralidade de respostas e de que muitos não sabiam o que responder, colocando apenas uma palavra ou região, 35

\footnotetext{
${ }^{41}$ Brandão, André et alli (2010). Comunidades quilombolas no Brasil, Niterói: Editora da UFF, p. 22.
} 
se consideravam ligados aos temas do rural, acionando palavras explicitamente ligadas ao tema (agricultura, colonização, colônia, coronelismo, estrutura fundiária, etc.).

Pesquisadores que responderam ao questionário

\begin{tabular}{|l|l|l|}
\hline Total de pesquisadores & $\begin{array}{l}\text { Total dos que responderam acerca da } \\
\text { linha de pesquisa }\end{array}$ & $\begin{array}{l}\text { dos que se consideram estudiosos } \\
\text { de temas ligados ao rural }\end{array}$ \\
\hline 456 & 444 & $35-8,8 \%$ \\
\hline
\end{tabular}

Fonte: Tabela realizada a partir dos dados registrados em: Bezerra, Holien \& Santos, Edilson dos. Quem é quem na História. Pesquisadores e Pesquisas no Brasil. Goiânia, ANPUH-CNPq, 1996.

Além disso, eu agrupei as palavras-chave que aparecem mais de 10 vezes, excluindo as palavras ligadas à região (Goiás, Rio de Janeiro) e agrupando palavraschaves com o mesmo sentido (trabalho/trabalhador). Por razões que me parecem óbvias, eu também não considerei as palavras-chaves que se referiam a cortes cronológicos.

PALAVRAS CHAVE CITADAS MAIS DE DEZ VEZES NO AGRUPAMENTO

\begin{tabular}{|c|c|}
\hline INTELECTUAIS & 10 \\
\hline MOVIMENTOS SOCIAIS & 10 \\
\hline SEXUALIDADE & 10 \\
\hline DOCUMENTACAO/FONTE & 11 \\
\hline ESTADO & 11 \\
\hline IMPRENSA & 11 \\
\hline METODOLOGIA & 11 \\
\hline MILITAR & 11 \\
\hline SINDICALISMO/SINDICATOS & 11 \\
\hline AGRICULTURA & 12 \\
\hline ARTE & 12 \\
\hline COLONIZAÇAO & 12 \\
\hline FAMILIA & 12 \\
\hline IDENTIDADE & 12 \\
\hline INDÚSTRIA/INDUSTRIALIZAÇÁOO & 12 \\
\hline CIDADE (s) & 13 \\
\hline COTIDIANO & 13 \\
\hline DEMOCRACIA & 13 \\
\hline IMAGINARIO & 13 \\
\hline URBANISMO/URBANIZAÇĀO & 13 \\
\hline RELIGIÁO/RELIGIOSIDADE & 14 \\
\hline ECONOMIA & 18 \\
\hline INDIGENA/INDIO & 19 \\
\hline IMIGRAÇĀO & 20 \\
\hline MODERNIDADE & 21 \\
\hline PODER & 21 \\
\hline IGREJA & 24 \\
\hline MEMÓRIA & 24 \\
\hline REVOLUÇÃO & 27 \\
\hline
\end{tabular}




\begin{tabular}{|c|l|}
\hline MULHER & 29 \\
\hline TRABALHADOR/RABALHO & 30 \\
\hline POLITICA & 31 \\
\hline ESCRAVIDAO & 36 \\
\hline CULTURA & 39 \\
\hline EDUCAÇAO/ENSINO & 45 \\
\hline HISTORIOGRAFIA & 49 \\
\hline
\end{tabular}

Fonte: Tabela realizada a partir dos dados registrados em: Bezerra, Holien \& Santos, Edilson dos. Quem é quem na História. Pesquisadores e Pesquisas no Brasil. Goiânia, ANPUH-CNPq, 1996.

Mais do que a óbvia consagração de temas ligados ao que podemos denominar de história cultural, por mais indefinido que seja tal denominação, mas presentes indiscutivelmente na importância das palavras-chave cultura, memória e modernidade, é sintomático também perceber como as ligadas à linha de pesquisa em história agrária são também elencadas, anunciando ao mesmo tempo a autonomia de dois sub-campos nos anos 90: a história social da escravidão e a história indígena. A palavra escravidão aparece 39 vezes, só perdendo para a junção educação/ensino e para historiografia. Em fins dos anos 80, quando da criação da linha de pesquisa em História Agrária na Universidade Federal Fluminense, a questão do cativo e também a do índio era parte de uma reflexão sobre o acesso à terra e era nesta perspectiva que muitos daquela geração se inseriam para escrever uma história dos pobres do campo ${ }^{42}$. Os seis pesquisadores que afirmaram explicitamente que estavam ligados à linha em história agrária propriamente dita, tiveram sua formação acadêmica na UFF. São eles: Francisco Carlos Teixeira da Silva, Hebe Mattos, Sheila de Castro, Monica de Oliveira, Valdir Gregory, e Paulo Zarth. Apenas uma historiadora, no entanto, apontou a inserção história agrária/escravidão: Hebe Mattos.

A presença dos conceitos centrais da discussão teórica proposta por Ciro Cardoso e/ou visíveis nos debates políticos do período são, porém, insignificantes. O conceito de campesinato aparece apenas duas vezes e termos como brecha camponesa e protocampesinato não estão citados uma única vez. O termo Reforma Agrária aparece uma única vez nas respostas ao questionário feitas pelo historiador Eudes Fernando Leite.

Uma conclusão, ainda que provisória.

\footnotetext{
42 Para não deixar dúvidas: eu também não utilizei de nenhum destes conceitos, quando respondi ao questionário.
} 
É possível que a pouca presença de termos como campesinato, brecha camponesa ou mesmo de Reforma Agrária seja o resultado de um processo histórico que pareceria se desdobrar no fim automático do campesinato, principalmente a partir dos anos 60. A maioria dos historiadores de tradição marxista apostara suas fichas naquela assertiva. O mais importante historiador marxista - Caio Prado Jr -havia destacado a pontualidade da reforma agrária no âmbito dos interesses dos trabalhadores rurais. Logo, é razoável inferir que a consagração daquele importante autor tenha desestimulado os estudos sobre o rural e a história das lutas camponesas no país. Além disso, o protagonismo da escravidão na sociedade brasileira do oitocentos certamente estimulou pesquisas sobre o passado escravista do país, num sem-número de obras sobre o tema, publicadas nos anos 90 .

Em segundo lugar, a afirmação da linha de história cultural no Brasil, não somente produziu um refinamento na narrativa do texto histórico, como também desnudou os limites das reflexões oriundas do aporte teórico dos marxistas daqueles anos. As concepções então defendidas por Ciro Cardoso e Jacob Gorender, como exemplos, ainda eram marcadas por um marxismo pouco afeito às dimensões culturais nos processos de resistência e negociações nos conflitos ${ }^{43}$. Além disso, a chegada da micro-história no país esteve muito mais voltada para temas ligados à religiosidade popular do que as variadas e distintas histórias da luta pela terra, nos distintos quinhões do que hoje chamamos de Brasil. Assim, é sintomático perceber como aquela linha do que poderíamos nominar de história cultural não incorporou temáticas propriamente agrárias no campo de sua reflexão. A maior parte dos pesquisadores brasileiros que seria reconhecida nos anos 90 como expressão desta linha de reflexão eram estudiosos da literatura e da cultura operária, ou mesmo dos escravos das cidades, como a emblemática obra de Sidney Chalhoub, em Visões da Liberdade ${ }^{44}$.

Em terceiro e último lugar, como nos lembrou a socióloga Maria Nazaré Wardeley, num texto apresentado em 1996, o chileno Jacques Chonchol reclamou da ausência, na historiografia brasileira, de uma história social do campesinato no país ${ }^{45}$. Ainda segundo a

\footnotetext{
${ }^{43}$ Gorender, Jacob (1980). O escravismo colonial. 3ae edição, São Paulo: Ática.

${ }^{44}$ Chalhoub, Sidney (1990). Visões da Liberdade, São Paulo: Companhia das Letras.

${ }^{45}$ Wanderley, Maria de Nazareth (1996). "Raízes Históricas do Campesinato Brasileiro". XX Encontro Anual da ANPUCS. GT 17. Processos Sociais Agrários, Caxambu. Chunchol foi ministro da cultura do governo de Allende, onde defendeu a reforma agrária. Vide a entrevista que ele concedeu ao Alfredo Bosi em 1994 e
} 
autora, é preciso sempre lembrar que a produção individual moderna tem sua origem e generalização(e eu diria, também sua legitimidade) no curso da história contemporânea. No entanto, tal como nos alerta Polanyi e mais recentemente Elen Wood, isso não foi gratuito; foi antes uma imposição do capitalismo que consagrou a propriedade privada, ao condenar ao desaparecimento, as formas de vida camponesas. Assim, e para finalizar, é verdade que os historiadores não estudam o passado para vender profecias. Mas é preciso ficar atento as nossas escolhas e a razões pelas quais nos distanciamos de temas tão candentes, como este da reforma agrária e do campesinato no Brasil dos anos 80 e 90, recorrentes e visíveis no contexto da redemocratização do país, mas sem a presença marcante da História.

\section{Referências Bibliográficas}

Biblioteca Nacional. Correio da Manhã, 01 de janeiro de 1964.

Brandão, André et alli (2010). Comunidades quilombolas no Brasil, Niterói: Editora da UFF.

Bruno, Regina (1997). Senhores da terra, senhores da guerra: a nova face política das elites agroindustriais no Brasil, Rio de Janeiro:Forense Universitária.

Bruno, Regina (1995). "O Estatuto da Terra: entre a conciliação e o confronto". In Estudos Sociedade e Agricultura (UFRJ), v. 4, p. 5-31.

Cardoso, Ciro (1979). Agricultura, Escravidão e Capitalismo, Petrópolis: Vozes.

Chalhoub, Sidney (1990). Visões da Liberdade, São Paulo: Companhia das Letras.

Choncho, Jacques (1994). "Entrevista. O Chile ontem e hoje". In Estudos Avançados. Vol. 8 no.21 São Paulo May/Aug.

Constituição do Brasil (2004) Rio de Janeiro:Editora Auriverde.

Eduardo Archetti et alli (1970). "Agrarian Structure and Peasant Autonomy". In Journal of Peace Research7(3): 185-195.

publicada pela revista Estudos Avançados. Chonchol, Jacques (1994). "Entrevista. O Chile ontem e hoje" Estudos Avançados. vol.8 no.21 São Paulo May/Aug. 
Gorender, Jacob (1980). O escravismo colonial. 3ª edição, São Paulo: Ática.

Melo, Maria da Conceição D’Incaio (1975). O Bóia-Fria. Acumulação e Miséria, Petrópolis: Vozes.

Moore Junior, Barrignton (1983). As origens sociais da ditadura e da democracia. Senhores e Camponeses na construção do mundo moderno, São Paulo: Martins Fontes.

Motta, Márcia; Esteves, Carlos Leandro (2008). "Ligas Camponesas: História de uma luta (des)conhecida". In Motta, Márcia; Zarth, Paulo. Formas de resistência camponesa. vol. II. São Paulo, UNESP, 243-257.

Motta, Márcia (2006). "Brecha negra em livro Branco: artigo 68, remanescentes de quilombos e grilagens no Brasil”. In Mendonça, Sonia. Estado e historiografia no Brasil, Niterói: EDUFF, p. 231-255.

Motta, Márcia (2010). "O rural na História do Brasil (dos anos 80 aos trabalhos mais recentes)". In Revista Portuguesa de História, Coimbra, p. 175-191.

Neves, Delma Pessanha (1997). Assentamento rural: reforma agrária em migalhas, Niterói: EDUFF.

Oliveira, Francisco de (2003). Crítica À Razão Dualista - O Ornitorrinco, Boitempo.

Prado Jr, Caio (1996). A Revolução Brasileira. 2ª edição, São Paulo: Editora Brasiliense.

Rangel, Socorro (2000). Medo da morte e esperança de vida: uma história das Ligas Camponesas. Dissertação (Mestrado em História) - UNICAMP.

Sidney Mintz (1974). "The Origins of Reconstituted Peasantries". In Caribbean Transformation. Chicago, Aldine, p. 146-156.

Sidney Mintz (2003). O poder amargo do açúcar, Recife: Editora da Universidade Federal de Pernambuco.

Silva, José Gomes da Silva (1989). Buraco Negro. A Reforma Agrária a Constituinte, Rio de Janeiro: Paz e Terra.

Silva, José Graziano da (1985). Para entender o Plano de Reforma Agrária, Petrópolis: Vozes.

Veiga, José Eli da (1990). A Reforma que virou suco. Uma introdução ao dilema agrário do Brasil.

Wanderley, Maria de Nazareth (1996). "Raízes Históricas do Campesinato Brasileiro". In XX Encontro Anual da ANPUCS. GT 17. Processos Sociais Agrários, Caxambu. 
Wood, Elen (2001). A origem do capitalismo, Rio de Janeiro: Jorge Zahar.

Site:

http://resistenciamilitar.blogspot.com.br/2011/03/reforma-agraria-questao-deconsciencia.html. Retirado em 03 de setembro de 2013.

http://ccatolico.qualinfonet.com.br/site/?p=5599 Retirado em 03 de setembro de 2013

LEI № 4.504, DE 30 DE NOVEMBRO DE 1964.

http://www.planalto.gov.br/ccivil 03/leis/L4504compilada.htm

Recebido para publicação em 04 de outubro de 2013.

Aprovado para publicação em 06 de novembro de 2013. 